\title{
Clinical Characteristics of Nonobese Patients with Acute Coronary Syndrome and Increased Epicardial Fat Volume
}

\author{
Ken Harada ${ }^{1}$, Hitomi Suzuki ${ }^{1}$, Shun Matsunaga ${ }^{1}$, Tomohiro Onishi ${ }^{1}$, Yoshinori Nishikawa ${ }^{1}$, Hiroshi Funakubo ${ }^{1}$, \\ Kumiko Mamiya ${ }^{1}$, Tomoyuki Nagao ${ }^{1}$, Norihiro Shinoda ${ }^{1}$, Shinichi Sakai ${ }^{1}$, Masataka Kato ${ }^{1}$, Nobuyuki Marui ${ }^{1}$, \\ Hideki Ishii ${ }^{2}$, Tetsuya Amano ${ }^{3}$, Tatsuaki Matsubara ${ }^{4}$ and Toyoaki Murohara²
}

\author{
${ }^{1}$ Department of Cardiology, Chubu Rosai Hospital, Nagoya, Japan \\ ${ }^{2}$ Department of Cardiology, Nagoya University Graduate School of Medicine, Nagoya, Japan \\ ${ }^{3}$ Department of Cardiology, Aichi Medical University Hospital, Aichi, Japan \\ ${ }^{4}$ Department of Internal Medicine, Aichi-Gakuin School of Dentistry, Nagoya, Japan
}

Aim: Increased epicardial fat volume (EFV) is an independent risk factor for acute coronary syndrome (ACS). Although EFV increases with body mass index (BMI), some ACS patients have an increased EFV but normal BMI. We here investigated the clinical characteristics of nonobese ACS patients with an increased EFV.

Methods: A total of 197 Japanese patients hospitalized for ACS was evaluated for EFV, abdominal visceral fat area (VFA), and lipid and glucose profiles. Control subjects comprised 141 individuals who were suspected of having ACS but whose coronary computed tomography findings were normal.

Results: EFV was increased in ACS patients compared with control subjects $(120 \pm 47$ versus $95 \pm 45 \mathrm{~mL}, P<$ $0.01)$. ACS patients were divided into four groups based on average EFV $(120 \mathrm{~mL})$ and a BMI obesity cutoff of $25 \mathrm{~kg} / \mathrm{m}^{2}$. For the 30 nonobese ACS patients with an above-average EFV, EFV was positively correlated with VFA $(r=0.23, P=0.031)$. These individuals were significantly older $(74 \pm 10$ years $)$ and tended to have a higher homeostasis model assessment-insulin resistance value (5.5 \pm 3.8$)$ compared with other ACS patients. Among nonobese study subjects, EFV was independently associated with ACS (odds ratio=2.01, $P=0.021$ ) and correlated with abdominal circumference $(r=0.26, P=0.017)$.

Conclusion: Nonobese ACS patients with an increased EFV were elderly and tended to manifest insulin resistance. Measurement of EFV may prove informative for evaluation of ACS risk among elderly nonobese individuals with an increased abdominal girth.

Key words: Epicardial fat, Acute coronary syndrome, Obesity, Insulin resistance

\section{Introduction}

Obesity is a risk factor for cardiovascular disease. However, adipose tissue distribution, rather than total body fat, has gained attention as a marker for cardiovascular risk ${ }^{1)}$. Numerous studies have thus shown that abdominal obesity associated with an excess of visceral fat is predictive of an increased risk for coronary artery disease $^{2-4}$. Japanese adults show a propensity for greater accumulation of visceral fat than of subcutaneous fat ${ }^{5}$. In addition, Japanese men have more abdominal vis- ceral fat compared with non-Hispanic white men after adjustment for differences in waist size ${ }^{6}$. Ectopic fat, such as that in the liver, has also been found to be more abundant in Japanese than in non-Hispanic white individuals, and this difference becomes more evident with a small increase in body mass index $(\mathrm{BMI})^{7)}$. Epicardial fat is a form of visceral adipose tissue that is deposited around the heart and, in contrast to abdominal visceral fat, is thought to promote coronary atherosclerosis directly through paracrine effects rather than through a systemic action ${ }^{8)}$. Chronic inflamma-

Address for correspondence: Ken Harada, Department of Cardiology, Chubu Rosai Hospital, 10-6 1-chome Komei, Minato-ku, Nagoya 455-8530, Japan 
tion in epicardial fat may influence the pathogenesis of coronary atherosclerosis ${ }^{9,10)}$. A causal relationship between epicardial adipose tissue and non-calcified plaque was reported ${ }^{11)}$; furthermore, an increased epicardial fat volume (EFV) has been shown to be an independent risk factor for acute coronary syndrome $(\mathrm{ACS})^{12}$. EFV tends to increase with BMI, but some individuals with ACS have an increased EFV but a normal BMI. Given that visceral fat accumulation is a major contributor to an increased risk of cardiovascular disease even in nonobese patients ${ }^{13)}$, we have now evaluated the clinical characteristics of nonobese ACS patients with an increased EFV.

\section{Methods}

\section{Subjects}

This retrospective cohort study assessed 223 consecutive patients who were hospitalized for ACS between June 2011 and November 2014. These individuals included patients with ST-elevated myocardial infarction (STEMI) and non-STEMI patients. STEMI patients were defined as individuals presenting with ischemic chest discomfort, an elevated ST-segment on the electrocardiogram, and an increased circulating troponin-I level, whereas individuals presenting with ischemic chest discomfort and an increased troponin-I level but without ST-segment elevation were classified as non-STEMI patients. The patients underwent coronary angiography, with the culprit lesions being identified on the basis of detection of pronounced stenosis ( $>90 \%$ obstruction). Coronary artery bypass graft surgery was deemed necessary for eight patients, and the remaining patients underwent percutaneous coronary intervention. All patients also underwent cardiac computed tomography (CT) during hospitalization as well as provided peripheral venous blood samples for analysis after an overnight fast. Lipid and glucose profiles were evaluated. In addition to those who underwent coronary artery bypass graft surgery $(n=8)$, we excluded patients who died after hospitalization $(n=2)$, who underwent implantation of a cardioverter defibrillator $(n=1)$, who required postoperative dialysis $(n=2)$, who did not regain consciousness after resuscitation for ventricular fibrillation $(n=2)$, who were found to have cancer after hospitalization $(n=1)$, or who did not undergo coronary angiography as recommended by the attending physician $(n=10)$. A total of 197 ACS patients was thus enrolled in the study. A control group consisted of 141 consecutive outpatients suspected of having ACS but found to have no obstructing stenosis during the same period. Blood analysis, electrocardiography, and cardiac CT examination were performed to evaluate symptoms of acute chest discomfort, but follow-up with invasive coronary angiography was not undertaken. The study was performed in accordance with the Declaration of Helsinki and was approved by the ethics review board of Chubu Rosai Hospital. All patients provided written informed consent.

\section{CT Image Analysis}

Epicardial fat content was determined on the basis of cardiac CT scans by two experienced analysts. EFV was defined as the total amount of adipose tissue between the surface of the heart and the visceral layer of the pericardium and was measured as described previously ${ }^{12)}$. The precise determination of the pericardium is not easy ${ }^{14}$. When we were unable to locate the pericardium precisely, we used a manual trace to observe the clearly determinable levels above and below the imprecise part. Then the software traced the imprecise part automatically. By performing a manual trace on as many levels as possible, we were able to decrease interobserver reliability. After confirming that the coronary artery was entirely contained within the region of interest in the volume rendering images, we determined EFV. Abdominal CT scans were also performed at the fourth to fifth lumbar levels. Visceral adipose tissue was analyzed in an image taken at the umbilicus level. Visceral fat area (VFA) was defined as intraperitoneal fat with attenuation ranging from -190 to -30 Hounsfield units and was measured with the use of dedicated software ${ }^{15)}$.

\section{Statistical Analysis}

Categorical and continuous variables are presented as the number (percentage) of individuals and as means $\pm S D$, respectively. Differences between two groups were evaluated with Student's unpaired $t$ test or the Mann-Whitney $U$ test for parameters with a normal or non-normal distribution, respectively, as determined with the Shapiro test. Differences among four groups were evaluated by analysis of variance (ANOVA) followed by Scheffe's test. The potential correlation of EFV with other clinical parameters was examined with Spearman's correlation coefficient by rank test. Logistic regression analysis was performed to determine whether clinical parameters were associated with ACS. A $P$ value of $<0.05$ was considered statistically significant. All statistical analysis was performed with the use of StatView for Windows software (Abacus Concepts, Berkeley, CA).

\section{Results}

Baseline Characteristics of the Study Subjects

The clinical characteristics of the study patients are shown in Table 1. Most patients with ACS were 
Table 1. Characteristics of ACS patients and control individuals

\begin{tabular}{|c|c|c|c|}
\hline Characteristic & ACS & Control & $P$ value \\
\hline All subjects & $(n=197)$ & $(n=141)$ & \\
\hline Age (years) & $65.5 \pm 12$ & $64.7 \pm 13$ & 0.293 \\
\hline Male, $n(\%)$ & $162(82)$ & $66(47)$ & $<0.01$ \\
\hline Weight (kg) & $66.5 \pm 13$ & $61.0 \pm 14$ & $<0.01$ \\
\hline BMI $\left(\mathrm{kg} / \mathrm{m}^{2}\right)$ & $24.6 \pm 3.6$ & $24.0 \pm 4.2$ & 0.239 \\
\hline Abdominal circumference $(\mathrm{cm})$ & $89.3 \pm 9.6$ & $87.5 \pm 13$ & 0.210 \\
\hline Systolic blood pressure $(\mathrm{mmHg})$ & $128 \pm 21$ & $137 \pm 20$ & $<0.01$ \\
\hline Diastolic blood pressure $(\mathrm{mmHg})$ & $74 \pm 14$ & $78 \pm 11$ & 0.061 \\
\hline Current smoker, $n(\%)$ & $107(54)$ & $36(26)$ & $<0.01$ \\
\hline \multicolumn{4}{|l|}{ Medical treatment } \\
\hline Hypertension, $n(\%)$ & $96(49)$ & $73(52)$ & 0.938 \\
\hline Type 2 diabetes, $n(\%)$ & $47(24)$ & $40(28)$ & 0.520 \\
\hline Dyslipidemia, $n(\%)$ & $59(30)$ & $56(40)$ & 0.130 \\
\hline \multicolumn{4}{|l|}{ Biochemical markers } \\
\hline Triglyceride (mg/dL) & $130 \pm 89$ & $158 \pm 98$ & 0.029 \\
\hline HDL-cholesterol (mg/dL) & $43 \pm 11$ & $52 \pm 14$ & $<0.01$ \\
\hline LDL-cholesterol (mg/dL) & $121 \pm 38$ & $116 \pm 32$ & 0.232 \\
\hline Triglyceride/HDL & $3.28 \pm 2.5$ & $3.38 \pm 2.5$ & 0.777 \\
\hline Hemoglobin A $A_{1 c}(\%)$ & $6.0 \pm 1.2$ & $6.1 \pm 1.8$ & 0.643 \\
\hline Uric acid (mg/dL) & $5.6 \pm 1.5$ & $5.5 \pm 1.7$ & 0.596 \\
\hline Creatinine $(\mathrm{mg} / \mathrm{dL})$ & $0.9 \pm 0.5$ & $0.8 \pm 0.4$ & 0.959 \\
\hline $\mathrm{BNP}(\mathrm{pg} / \mathrm{mL})$ & $197 \pm 246$ & $62 \pm 82$ & $<0.01$ \\
\hline VFA $\left(\mathrm{cm}^{2}\right)$ & $122 \pm 66$ & $104 \pm 65$ & 0.019 \\
\hline $\mathrm{EFV}(\mathrm{mL})$ & $120 \pm 47$ & $95 \pm 45$ & $<0.01$ \\
\hline Nonobese subjects (BMI $<25 \mathrm{~kg} / \mathrm{m}^{2}$ ) & $(n=109)$ & $(n=96)$ & \\
\hline Age (years) & $67.7 \pm 12$ & $65.1 \pm 13$ & 0.144 \\
\hline Male, $n(\%)$ & $82(75)$ & $43(45)$ & $<0.01$ \\
\hline Weight (kg) & $57.6 \pm 8.5$ & $55.8 \pm 9.5$ & 0.160 \\
\hline BMI $\left(\mathrm{kg} / \mathrm{m}^{2}\right)$ & $22.0 \pm 2.2$ & $22.1 \pm 2.1$ & 0.768 \\
\hline Abdominal circumference $(\mathrm{cm})$ & $87.1 \pm 9.8$ & $82.7 \pm 11$ & $<0.01$ \\
\hline Systolic blood pressure $(\mathrm{mmHg})$ & $126 \pm 22$ & $136 \pm 20$ & $<0.01$ \\
\hline Diastolic blood pressure (mmHg) & $73 \pm 15$ & $78 \pm 11$ & 0.010 \\
\hline Current smoker, $n(\%)$ & $56(51)$ & $25(26)$ & $<0.01$ \\
\hline \multicolumn{4}{|l|}{ Medical treatment } \\
\hline Hypertension, $n(\%)$ & $54(50)$ & $46(48)$ & 0.397 \\
\hline Type 2 diabetes, $n(\%)$ & $19(17)$ & $25(26)$ & 0.241 \\
\hline Dyslipidemia, $n(\%)$ & $25(23)$ & $33(34)$ & 0.153 \\
\hline \multicolumn{4}{|l|}{ Biochemical markers } \\
\hline Triglyceride (mg/dL) & $114 \pm 67$ & $143 \pm 94$ & 0.041 \\
\hline HDL-cholesterol (mg/dL) & $44 \pm 12$ & $53 \pm 13$ & $<0.01$ \\
\hline LDL-cholesterol (mg/dL) & $118 \pm 33$ & $110 \pm 32$ & 0.153 \\
\hline Triglyceride/HDL & $2.84 \pm 1.9$ & $2.98 \pm 2.2$ & 0.682 \\
\hline Hemoglobin Alc $(\%)$ & $5.8 \pm 0.9$ & $6.0 \pm 1.9$ & 0.356 \\
\hline Uric acid (mg/dL) & $5.4 \pm 1.6$ & $5.5 \pm 1.8$ & 0.758 \\
\hline Creatinine $(\mathrm{mg} / \mathrm{dL})$ & $0.9 \pm 0.4$ & $0.8 \pm 0.3$ & 0.899 \\
\hline $\mathrm{BNP}(\mathrm{pg} / \mathrm{mL})$ & $236 \pm 245$ & $73 \pm 93$ & $<0.01$ \\
\hline VFA $\left(\mathrm{cm}^{2}\right)$ & $90 \pm 39$ & $78 \pm 37$ & 0.044 \\
\hline $\mathrm{EFV}(\mathrm{mL})$ & $107 \pm 47$ & $86 \pm 35$ & $<0.01$ \\
\hline
\end{tabular}

Data are presented as means \pm SD or number (\%) of patients as indicated. $P$ values were determined with Student's $t$ test or the Mann-Whitney $U$ test. Abbreviations not defined in text: LDL, low density lipoprotein; BNP, brain natriuretic peptide. 
Table 2. Correlations between EFV and other clinical parameters for ACS patients and control subjects

\begin{tabular}{|c|c|c|c|c|}
\hline \multirow{2}{*}{ Parameter } & \multicolumn{2}{|c|}{ ACS } & \multicolumn{2}{|c|}{ Control } \\
\hline & $r$ & $P$ value & $r$ & $P$ value \\
\hline All subjects & \multicolumn{2}{|c|}{$(n=197)$} & \multicolumn{2}{|c|}{$(n=141)$} \\
\hline Age (years) & 0.11 & 0.112 & 0.20 & 0.018 \\
\hline BMI $\left(\mathrm{kg} / \mathrm{m}^{2}\right)$ & 0.41 & $<0.01$ & 0.50 & $<0.01$ \\
\hline Abdominal circumference $(\mathrm{cm})$ & 0.30 & $<0.01$ & 0.49 & $<0.01$ \\
\hline Triglyceride (mg/dL) & 0.16 & 0.030 & 0.11 & 0.301 \\
\hline HDL-cholesterol (mg/dL) & -0.08 & 0.275 & -0.10 & 0.371 \\
\hline LDL-cholesterol (mg/dL) & 0.01 & 0.980 & 0.17 & 0.123 \\
\hline Hemoglobin A1c (\%) & 0.03 & 0.679 & 0.05 & 0.638 \\
\hline Hs-CRP (mg/dL) & 0.05 & 0.490 & 0.12 & 0.278 \\
\hline VFA $\left(\mathrm{cm}^{2}\right)$ & 0.52 & $<0.01$ & 0.62 & $<0.01$ \\
\hline Nonobese subjects & \multicolumn{2}{|c|}{$(n=109)$} & \multicolumn{2}{|c|}{$(n=96)$} \\
\hline Age (years) & 0.21 & 0.032 & 0.13 & 0.209 \\
\hline BMI $\left(\mathrm{kg} / \mathrm{m}^{2}\right)$ & 0.32 & $<0.01$ & 0.40 & $<0.01$ \\
\hline Abdominal circumference $(\mathrm{cm})$ & 0.26 & 0.017 & 0.20 & 0.060 \\
\hline Triglyceride (mg/dL) & 0.22 & 0.023 & 0.01 & 0.952 \\
\hline HDL-cholesterol (mg/dL) & -0.12 & 0.231 & -0.03 & 0.846 \\
\hline LDL-cholesterol (mg/dL) & 0.06 & 0.510 & 0.08 & 0.560 \\
\hline Hemoglobin A1c (\%) & 0.06 & 0.554 & 0.34 & 0.010 \\
\hline Hs-CRP (mg/dL) & 0.13 & 0.177 & 0.05 & 0.748 \\
\hline VFA $\left(\mathrm{cm}^{2}\right)$ & 0.53 & $<0.01$ & 0.27 & $<0.01$ \\
\hline
\end{tabular}

Abbreviations not defined previously: $r$, correlation coefficient; Hs-CRP, high-sensitivity C-reactive protein.

male and current smokers. BMI was $24.6 \pm 3.6$ and $24.0 \pm 4.2 \mathrm{~kg} / \mathrm{m}^{2}$ for the ACS and control groups, respectively, with the difference between the two groups not being statistically significant. Patients with ACS had lower serum triglyceride and high density lipoprotein (HDL) - cholesterol levels compared with the control subjects. The culprit vessels for ACS included the right coronary artery in 68 patients, left main coronary trunk in 2 patients, left anterior descending coronary artery in 102 patients, and left circumflex coronary artery in 25 patients. The average duration of hospitalization for the ACS patients was 13.2 \pm 5.6 days. EFV was significantly increased in the ACS group compared with the control group (120 \pm 47 versus $95 \pm 45$ $\mathrm{mL}, P<0.01)$. Examination of only nonobese individuals $\left(B M I<25 \mathrm{~kg} / \mathrm{m}^{2}\right)$, patients with ACS had larger abdominal circumference, and increased VFA and EFV $\left(90 \pm 39\right.$ versus $78 \pm 37 \mathrm{~cm}^{2}, P=0.04 ; 107 \pm$ 47 versus $86 \pm 35 \mathrm{~mL}, P<0.01$, respectively) compared with the control subjects.

\section{Relation between EFV and Other Clinical Parame- ters}

In the ACS group, EFV was significantly correlated with BMI $(r=0.41, P<0.01)$, abdominal cir- cumference $(r=0.30, P<0.01)$, serum triglyceride level $(r=0.16, P=0.030)$, and VFA $(r=0.52, P<0.01)$ (Table $2)$. In the control group, EFV was significantly correlated with age $(r=0.20, P=0.018)$, BMI $(r=0.50, P<$ $0.01)$, abdominal circumference $(r=0.49, P<0.01)$, and VFA $(r=0.62, P<0.01)$. Although EFV was positively correlated with BMI, abdominal circumference, and VFA in both groups, the correlation coefficients were greater for the control subjects than for the ACS patients. Analysis of only nonobese individuals (BMI $<25 \mathrm{~kg} / \mathrm{m}^{2}$ ), however, revealed that the correlation coefficients between EFV and BMI, VFA were greater for the ACS patients than for the control subjects and that EFV was significantly correlated with abdominal circumference and serum triglyceride level in ACS patients $(r=0.26, P=0.017 ; r=0.22, P=0.023$, respectively) but not in control subjects.

Factors Independently Associated with ACS in Nonobese Individuals

Logistic regression analysis was performed to assess the independent association of clinical parameters with ACS among nonobese subjects (Table 3). An EFV of $>100 \mathrm{~mL}$ (the cutoff value in our previous study ${ }^{12)}$ ), a serum HDL-cholesterol concentration of 
Table 3. Logistic regression analysis for factors related to ACS among nonobese subjects

\begin{tabular}{|c|c|c|c|c|}
\hline \multirow{2}{*}{ Variable } & \multicolumn{2}{|c|}{ Univariate } & \multicolumn{2}{|c|}{ Multivariate } \\
\hline & OR (95\% CI) & $P$ value & OR $(95 \% \mathrm{CI})$ & $P$ value \\
\hline Age $>66$ years (median) & $1.11(0.64-1.93)$ & 0.709 & & \\
\hline Sex, male & $3.30(1.84-5.90)$ & $<0.01$ & & \\
\hline Current smoker & $3.01(1.66-5.45)$ & $<0.01$ & $3.16(1.57-6.35)$ & $<0.01$ \\
\hline HDL-chol $<40 \mathrm{mg} / \mathrm{dL}$ & $2.95(1.38-6.30)$ & $<0.01$ & $2.67(1.22-5.85)$ & 0.014 \\
\hline LDL-chol > $120 \mathrm{mg} / \mathrm{dL}$ & $1.14(0.59-2.23)$ & 0.685 & $1.26(0.63-2.53)$ & 0.507 \\
\hline Hemoglobin $A_{l c}>6.5 \%$ & $1.08(0.43-2.70)$ & 0.859 & $0.93(0.35-2.44)$ & 0.884 \\
\hline VFA $>100 \mathrm{~cm}^{2}$ & $1.48(0.78-2.81)$ & 0.223 & $1.29(0.66-2.53)$ & 0.452 \\
\hline $\mathrm{EFV}>100 \mathrm{~mL}$ & $1.01(1.00-1.02)$ & $<0.01$ & $2.01(1.11-3.70)$ & 0.021 \\
\hline
\end{tabular}

Multivariate logistic regression analysis was performed with adjustment for age and sex. Abbreviations not defined previously: OR, odds ratio; CI, confidence interval; chol, cholesterol.

$<40 \mathrm{mg} / \mathrm{dL}$ and current smoking were found to be independently associated with ACS (odds ratio $=2.01$, $P=0.021$; odds ratio $=2.67, P=0.014$; and odds ratio $=$ $3.16, P<0.01$, respectively). A VFA of $>100 \mathrm{~cm}^{2}$ was not a significant factor. Epicardial fat was thus more strongly associated with ACS than was abdominal visceral fat in nonobese individuals.

\section{Clinical Characteristics of Nonobese ACS Patients with an Increased EFV}

Given that we found that EFV was positively correlated with BMI in both ACS and control groups (Table 2, Fig. 1) and that obesity in Japan is defined as a BMI of $>25 \mathrm{~kg} / \mathrm{m}^{216}$, we divided the ACS patients into four groups on the basis of mean EFV (120 $\mathrm{mL}$ ) and the BMI cutoff for obesity $\left(25 \mathrm{~kg} / \mathrm{m}^{2}\right)$ : nonobese with an above-average EFV (group I), nonobese with a below-average EFV (group II), obese with an above-average EFV (group III), and obese with a belowaverage EFV (group IV). Group I comprised 30 patients (age of $74 \pm 10$ years, $73 \%$ men) with an abdominal VFA of $114 \pm 42 \mathrm{~cm}^{2}$. A significant correlation between EFV and abdominal VFA was apparent among these patients $(r=0.23, P=0.031), 7(23 \%)$ of whom met the diagnostic criteria for metabolic syndrome. Moreover, the patients in group I were older $(P<0.01)$ and tended to have a higher homeostasis model assessment-insulin resistance value $(5.5 \pm 3.8, P=0.091) \mathrm{com}$ pared with those in the other three groups (Table 4).

\section{Discussion}

The principal findings of our study are threefold. First, nonobese ACS patients with an increased EFV were elderly and tended to show increased insulin resistance compared with other ACS patients. Second, nonobese patients with ACS had an increased EFV com- pared with nonobese control subjects, and their EFV was positively correlated with serum triglyceride level and abdominal circumference. Third, EFV was independently associated with ACS in nonobese individuals. These findings suggest that individuals with increased insulin resistance despite a normal BMI may have an increased EFV and associated increased risk for developing ACS. Complications of obesity are more related to visceral adiposity than to excess body fat per se, with an increased abdominal adipose tissue content having been shown to be associated with adverse changes in risk factors for cardiovascular disease even after adjustment for BMI ${ }^{17}$.

Insulin resistance is associated with elevated triglyceride levels, high blood pressure, and type 2 diabetes as well as with reduced levels of HDL-cholesterol $^{18)}$. It has also been shown to predict cardiovascular disease events ${ }^{19)}$. Although insulin resistance is correlated with BMI, normal-weight individuals may also be insulin resistant, suggesting that overall adiposity is not its sole determinant ${ }^{20)}$. Indeed, insulin resistance is more strongly associated with abdominal obesity than with BMI. Waist circumference is often measured as a marker of abdominal obesity, and we found that EFV was positively correlated with abdominal circumference in nonobese ACS patients. Measurement of abdominal girth may, therefore, be useful for ACS risk assessment even in nonobese individuals.

Pericardial fat is a local deposit of visceral fat surrounding the heart and coronary arteries that may exacerbate vessel wall inflammation and promote the progression of atherosclerosis via outside-to-inside signaling ${ }^{2122)}$. The abundance of pericardial fat was found to be increased in patients with coronary atherosclerosis including nonobese individuals ${ }^{23)}$. Ectopic deposition of fat in the liver or muscle tissue is thought to be an important factor in the development of insulin resis- 
A

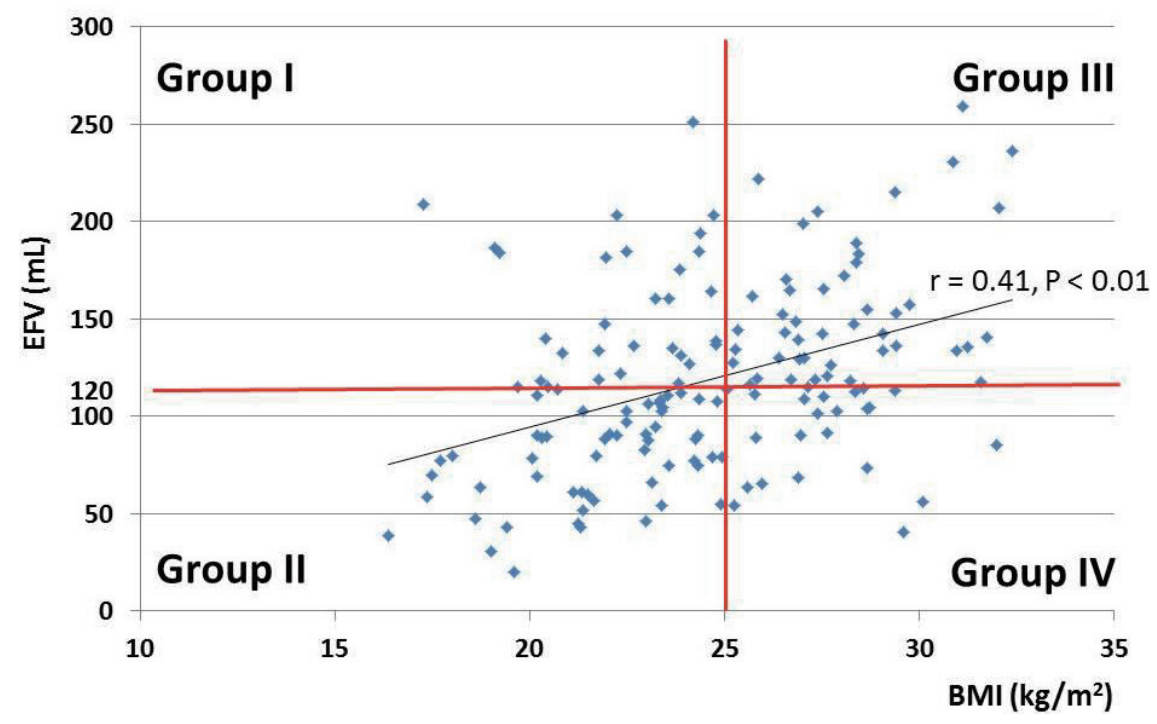

B

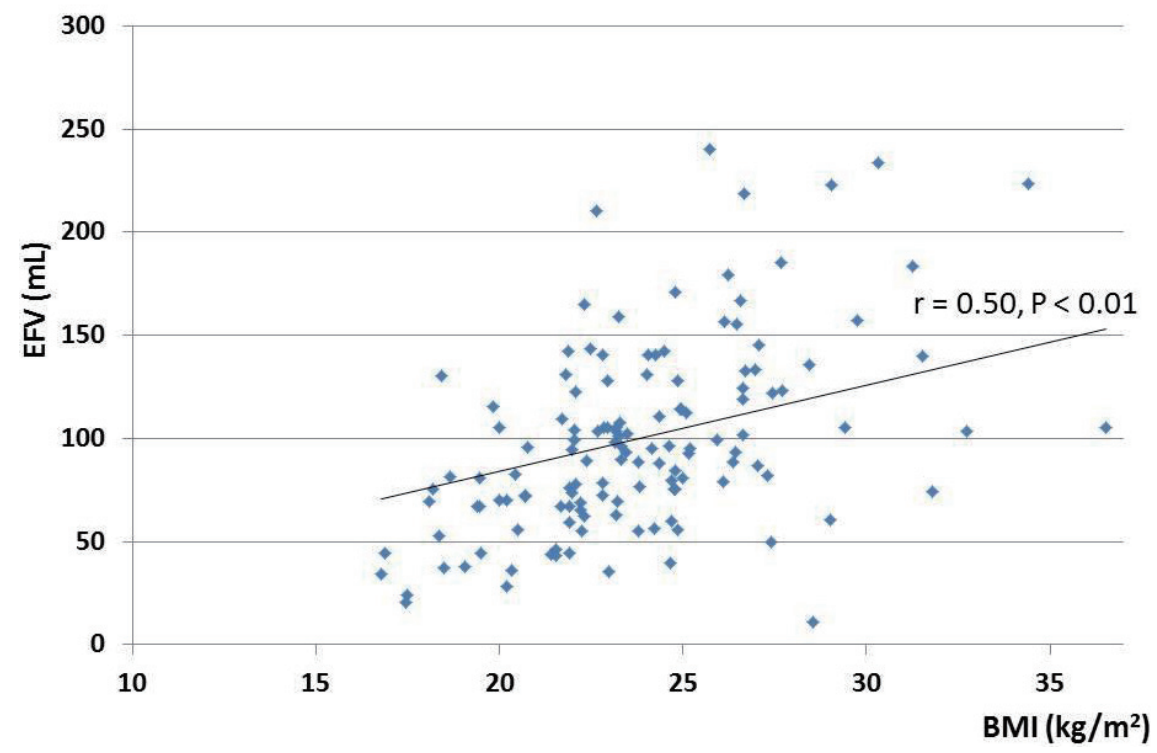

Fig. 1. Correlation between EFV and BMI in ACS patients (A) and control subjects (B). Values for individual ACS patients are shown according to classification into groups I to IV based on average EFV $(120 \mathrm{~mL})$ and a BMI cutoff of $25 \mathrm{~kg} / \mathrm{m}^{2}$.

tance ${ }^{24,25)}$. Moreover, an increased bioactive lipid content in human subcutaneous and epicardial fat tissue correlates with insulin resistance ${ }^{26}$. Insulin resistance in adipose tissue manifests as impairment of the stimulatory and inhibitory effects of insulin on glucose transport and lipolysis, respectively.
Accumulation of excess ectopic fat is an important risk factor for many diseases - including hypertension, type 2 diabetes, dyslipidemia, and atherosclerosis - as a result of the associated production of angiotensinogen and angiotensin II, activation of inflammation, and reduced levels of adiponectin ${ }^{27)}$. Adipocy- 
Table 4. Characteristics of ACS patients classified into four groups based on average EFV (120 mL) and the BMI cutoff for obesity $\left(25 \mathrm{~kg} / \mathrm{m}^{2}\right)$

\begin{tabular}{|c|c|c|c|c|c|}
\hline & $\begin{array}{l}\text { Group I } \\
(n=30)\end{array}$ & $\begin{array}{c}\text { Group II } \\
(n=77)\end{array}$ & $\begin{array}{c}\text { Group III } \\
(n=56)\end{array}$ & $\begin{array}{c}\text { Group IV } \\
(n=34)\end{array}$ & $P$ value \\
\hline Age (years) & $74 \pm 10$ & $66 \pm 12$ & $61 \pm 12$ & $57 \pm 12$ & $<0.01$ \\
\hline Male, $n(\%)$ & $22(73)$ & $58(75)$ & $53(95)$ & $31(91)$ & $<0.01$ \\
\hline BMI $\left(\mathrm{kg} / \mathrm{m}^{2}\right)$ & $23 \pm 2.0$ & $22 \pm 2.1$ & $28 \pm 2.3$ & $27 \pm 1.7$ & $<0.01$ \\
\hline Current smoker, $n(\%)$ & $16(53)$ & $32(42)$ & $32(57)$ & $19(56)$ & 0.959 \\
\hline Metabolic syndrome, $n(\%)$ & $7(23)$ & $9(12)$ & $35(63)$ & $13(38)$ & $<0.01$ \\
\hline Abdominal circumference $(\mathrm{cm})$ & $87 \pm 5.5$ & $82 \pm 6.8$ & $98 \pm 7.5$ & $93 \pm 6.6$ & $<0.01$ \\
\hline VFA $\left(\mathrm{cm}^{2}\right)$ & $114 \pm 42$ & $89 \pm 36$ & $169 \pm 68$ & $147 \pm 73$ & $<0.01$ \\
\hline LDL-cholesterol (mg/dL) & $113 \pm 28$ & $120 \pm 36$ & $121 \pm 35$ & $131 \pm 53$ & 0.328 \\
\hline HDL-cholesterol (mg/dL) & $43 \pm 11$ & $44 \pm 12$ & $42 \pm 8.3$ & $42 \pm 10$ & 0.403 \\
\hline Triglyceride $(\mathrm{mg} / \mathrm{dL})$ & $118 \pm 66$ & $111 \pm 67$ & $143 \pm 70$ & $137 \pm 85$ & 0.056 \\
\hline Hemoglobin $A_{1 c}(\%)$ & $5.7 \pm 1.0$ & $5.8 \pm 0.9$ & $6.3 \pm 1.3$ & $6.2 \pm 1.6$ & 0.042 \\
\hline HOMA-IR & $5.5 \pm 3.8$ & $2.7 \pm 4.4$ & $4.3 \pm 4.4$ & $2.8 \pm 1.9$ & 0.091 \\
\hline $\mathrm{EFV}(\mathrm{mL})$ & $168 \pm 35$ & $84 \pm 22$ & $161 \pm 35$ & $96 \pm 23$ & $<0.01$ \\
\hline
\end{tabular}

Data are presented as means \pm SD or number $(\%)$ of patients as indicated. $P$ values were determined by ANOVA followed by Scheffe's test. Abbreviations not defined previously: HOMA-IR, homeostasis model assessment-insulin resistance. Group I, above-average EFV and nonobese; group II: below-average EFV and nonobese; group III, above-average EFV and obese; group IV, below-average EFV and obese.

tokines secreted from perivascular adipocytes have been proposed to inhibit insulin signaling via the phosphatidylinositol 3-kinase pathway in vascular endothelial cells and thereby to leave unopposed the vasoconstrictor effect of endothelin- ${ }^{22)}$. Reduced insulin-mediated enhancement of muscle nutritive blood flow contributes to insulin resistance. We have now found that insulin resistance tended to be increased in nonobese ACS patients with an increased EFV, suggesting that accumulation of epicardial fat may be related to insulin resistance in nonobese ACS patients.

In this study, the number of current smokers was increased in the ACS group. The association between EFV and smoking has not been elucidated. However, epicardial adipose tissue levels of TNF- $\alpha$ and IL- 6 were significantly elevated in current smokers when compared with never smokers and former smokers ${ }^{28)}$, which supports the mechanism that epicardial adipose tissue in smokers could contribute to the pathogenesis of adverse effects of tobacco smoking.

There are several limitations to the present study. First, some biomarkers related to insulin resistance, such as fasting plasma glucose and insulin concentrations, were not measured in the control subjects because not all of them had fasted before visiting the hospital. Comparison of insulin resistance between ACS patients and the control subjects was thus not possible. The ratio of triglyceride to HDL-cholesterol has been proposed as a surrogate marker of insulin resistance ${ }^{29)}$. In this study subject, there was no significant difference in triglyceride/HDL ratio between two groups
(Table 1). Furthermore, triglyceride/HDL ratio was not an independent associated factor (odds ratio $=1.02, P=$ $0.824)$ for ACS in nonobese subjects. It might be due to the high diabetic prevalence in the control group. Even in nondiabetic patients, insulin resistance progresses in parallel with heart failure and impaired functional capacity of the cardiovascular system ${ }^{30)}$. Second, nonobese ACS patients had an increased serum concentration of brain natriuretic peptide compared with nonobese controls subjects (Table 1), suggesting that some of these ACS patients may have developed insulin resistance in association with complicated heart failure. Third, the cutoff of VFA was $100 \mathrm{~cm}^{2}$ for logistic regression analysis, in accordance with the diagnostic criteria of visceral fat obesity in Japan ${ }^{16)}$. However, Japanese have a greater amount of abdominal visceral fat relative to abdominal subcutaneous fat compared with Caucasians ${ }^{5)}$. Fourth, the study population was relatively small and was composed exclusively of Japanese subjects. More research is thus required to explore the implications of our findings for clinical practice.

\section{Conclusion}

We found that nonobese ACS patients with an increased EFV were elderly and tended to manifest insulin resistance. EFV was also identified as an independent related factor for ACS in nonobese individuals. In addition, among nonobese individuals, EFV was positively correlated with abdominal circumference in ACS patients but not in control subjects. Our 
results suggest that measurement of EFV on CT images may be informative for evaluation of the risk for ACS in elderly patients with an increased abdominal girth but who are not obese.

\section{Disclosures}

The authors declared they do not have anything to disclose regarding conflict of interest with respect to this manuscript.

\section{References}

1) Fox CS, Massaro JM, Hoffmann U, Pou KM, MaurovichHorvat P, Liu CY, Vasan RS, Murabito JM, Meigs JB, Cupples LA, D'Agostino RB Sr, and O'Donnell CJ: Abdominal visceral and subcutaneous adipose tissue compartments: association with metabolic risk factors in the Framingham Heart Study. Circulation, 2007; 116: 39-48

2) Hayashi T, Boyko EJ, Leonetti DL, McNeely MJ, NewellMorris L, Kahn SE, and Fujimoto WY: Visceral adiposity is an independent predictor of incident hypertension in Japanese Americans. Ann Intern Med, 2004; 140: $992-$ 1000

3) Boyko EJ, Fujimoto WY, Leonetti DL, and Newell-Morris L: Visceral adiposity and risk of type 2 diabetes: a prospective study among Japanese Americans. Diabetes Care, 2000; 23: 465-471

4) Abraham TM, Pedley A, Massaro JM, Hoffmann U, and Fox CS: Association between visceral and subcutaneous adipose depots and incident cardiovascular disease risk factors. Circulation, 2015; 132: 1639-1647

5) Tanaka S, Horimai C, and Katsukawa F: Ethnic differences in abdominal visceral fat accumulation between Japanese, African-Americans, and Caucasians: a metaanalysis. Acta Diabetol, 2003; 40 (suppl 1): S302-S304

6) Kadowaki T, Sekikawa A, Murata K, Maegawa H, Takamiya T, Okamura T, El-Saed A, Miyamatsu N, Edmundowicz D, Kita Y, Sutton-Tyrrell K, Kuller LH, and Ueshima $\mathrm{H}$ : Japanese men have larger areas of visceral adipose tissue than Caucasian men in the same levels of waist circumference in a population-based study. Int J Obes (Lond), 2006; 30: 1163-1165

7) Azuma K, Kadowaki T, Cetinel C, Kadota A, El-Saed A, Kadowaki S, Edmundowicz D, Nishio Y, Sutton-Tyrrell K, Okamura T, Evans RW, Takamiya T, Ueshima H, Curb JD, Abbott RD, Kuller LH, Kelley DE, Sekikawa A; ERA JUMP Study Group: Higher liver fat content among Japanese in Japan compared with non-Hispanic whites in the United States. Metabolism, 2009; 58: 1200-1207

8) Harada K, Amano T, Kataoka T, Takeshita M, Harada K, Kunimura A, Takayama Y, Shinoda N, Kato B, Uetani T, Kato M, Marui N, Ishii H, Matsubara T, and Murohara $\mathrm{T}$ : Impact of abdominal and epicardial fat on the association between plasma adipocytokine levels and coronary atherosclerosis in non-obese patients. Atherosclerosis, 2014; 237: 671-676

9) Hirata Y, Kurobe H, Akaike M, Chikugo F, Hori T, Bando Y, Nishio C, Higashida M, Nakaya Y, Kitagawa T, Sata M.
Enhanced inflammation in epicardial fat in patients with coronary artery disease. Int Heart J. 2011; 52: 139-142

10) Shimabukuro M, Hirata Y, Tabata M, Dagvasumberel M, Sato H, Kurobe H, Fukuda D, Soeki T, Kitagawa T, Takanashi S, Sata M. Epicardial adipose tissue volume and adipocytokine imbalance are strongly linked to human coronary atherosclerosis. Arterioscler Thromb Vasc Biol. 2013; 33: $1077-1084$

11) Hwang IC, Park HE, Choi SY. Epicardial Adipose Tissue Contributes to the Development of Non-Calcified Coronary Plaque: A 5-Year Computed Tomography Follow-up Study. J Atheroscler Thromb. 2017; 24: 262-274

12) Harada K, Amano T, Uetani T, Tokuda Y, Kitagawa K, Shimbo Y, Kunimura A, Kumagai S, Yoshida T, Kato B, Kato M, Marui N, Ishii H, Matsubara T, and Murohara T: Cardiac 64-multislice computed tomography reveals increased epicardial fat volume in patients with acute coronary syndrome. Am J Cardiol, 2011; 108: 1119-1123

13) Kobayashi H, Nakamura T, Miyaoka K, Nishida M, Funahashi T, Yamashita S, and Matsuzawa Y: Visceral fat accumulation contributes to insulin resistance, small-sized lowdensity lipoprotein, and progression of coronary artery disease in middle-aged non-obese Japanese men. Jpn Circ J, 2001; 65: 193-199

14) Yamada H, Sata M. Role of pericardial fat: The good, the bad and the ugly. J Cardiol. 2015; 65: 2-4

15) Yoshizumi T, Nakamura T, Yamane M, Islam AH, Menju M, Yamasaki K, Arai T, Kotani K, Funahashi T, Yamashita S, and Matsuzawa Y: Abdominal fat: standardized technique for measurement at CT. Radiology, 1999; 211: 283286

16) Takahashi $\mathrm{H}$ and Mori $\mathrm{M}$ : Characteristics and significance of criteria for obesity disease in Japan 2011. Nihon Rinsho, 2013; 71: 257-261

17) Lee JJ, Pedley A, Hoffmann U, Massaro JM, and Fox CS: Association of changes in abdominal fat quantity and quality with incident cardiovascular disease risk factors. J Am Coll Cardiol, 2016; 68: 1509-1521

18) Bonora E, Kiechl S, Willeit J, Oberhollenzer F, Egger G, Meigs JB, Bonadonna RC, and Muggeo M: Insulin resistance as estimated by homeostasis model assessment predicts incident symptomatic cardiovascular disease in Caucasian subjects from the general population: the Bruneck study. Diabetes Care, 2007; 30: 318-324

19) Jeppesen J, Hansen TW, Rasmussen S, Ibsen H, TorpPedersen $C$, and Madsbad S: Insulin resistance, the metabolic syndrome, and risk of incident cardiovascular disease: a population-based study. J Am Coll Cardiol, 2007; 49: 2112-2119

20) McLaughlin T, Allison G, Abbasi F, Lamendola C, and Reaven G: Prevalence of insulin resistance and associated cardiovascular disease risk factors among normal weight, overweight, and obese individuals. Metabolism, 2004; 53: 495-499

21) Mazurek T, Zhang L, Zalewski A, Mannion JD, Diehl JT, Arafat H, Sarov-Blat L, O’Brien S, Keiper EA, Johnson AG, Martin J, Goldstein BJ, and Shi Y: Human epicardial adipose tissue is a source of inflammatory mediators. Circulation, 2003; 108: 2460-2466

22) Yudkin JS, Eringa E, and Stehouwer CD: "Vasocrine" signalling from perivascular fat: a mechanism linking insulin 
resistance to vascular disease. Lancet, 2005; 365: 1817 1820

23) Yong HS, Kim EJ, Seo HS, Kang EY, Kim YK, Woo OH, and $\mathrm{Han} \mathrm{H}$ : Pericardial fat is more abundant in patients with coronary atherosclerosis and even in the non-obese patients: evaluation with cardiac CT angiography. Int J Cardiovasc Imaging, 2010; 26 (suppl 1): 53-62

24) Błachnio-Zabielska AU, Baranowski M, Hirnle T, Zabielski P, Lewczuk A, Dmitruk I, and Górski J: Increased bioactive lipids content in human subcutaneous and epicardial fat tissue correlates with insulin resistance. Lipids, 2012; 47: 1131-1141

25) Kelley DE and Mandarino LJ: Fuel selection in human skeletal muscle in insulin resistance: a reexamination. Diabetes, 2000; 49: 677-683

26) McGarry JD: Banting lecture 2001: dysregulation of fatty acid metabolism in the etiology of type 2 diabetes. Diabetes, $2002 ; 51: 7-18$
27) Lim S, Despres JP, and Koh KK: Prevention of atherosclerosis in overweight/obese patients. In need of novel multitargeted approaches. Circ J, 2011; 75: 1019-1027

28) Mach L, Bedanova H, Soucek M, Karpisek M, Nemec P, Orban M. Tobacco smoking and cytokine levels in human epicardial adipose tissue: Impact of smoking cessation. Atherosclerosis. 2016; 255: 37-42

29) Murguía-Romero M, Jiménez-Flores JR, Sigrist-Flores SC, Espinoza-Camacho MA, Jiménez-Morales M, Piña E, Méndez-Cruz AR, Villalobos-Molina R, Reaven GM. Plasma triglyceride/HDL-cholesterol ratio, insulin resistance, and cardiometabolic risk in young adults. J Lipid Res. 2013; 54: 2795-2799

30) Swan JW, Anker SD, Walton C, Godsland IF, Clark AL, Leyva F, Stevenson JC, and Coats AJ: Insulin resistance in chronic heart failure: relation to severity and etiology of heart failure. J Am Coll Cardiol, 1997; 30: 527-532 